\title{
Metabolic Profiling of Dunaliella salina Shifting Cultivation Conditions to Nitrogen Deprivation
}

\section{Lv $\mathrm{H}^{1,2 *}$, Cui $\mathrm{X}^{2}$, Wang $\mathrm{S}^{2}$ and Jia $\mathrm{S}^{2 *}$}

${ }^{1}$ Tianjin Key Laboratory of Marine Resources and Chemistry, Tianjin University of Science and Technology, Tianjin, 300457, P.R. China ${ }^{2}$ Key Laboratory of Industrial Fermentation Microbiology, Ministry of Education, Tianjin Key Lab of Industrial Microbiology, Tianjin University of Science and Technology, Tianjin, 300457, P.R. China

\begin{abstract}
Dunaliella salina is a model chlorophyte microalga in studying carotenoid metabolism and osmoregulation. Nitrogen depletion plays an important role in inducing $\beta$-carotene accumulation of $D$. salina cells. However, the underlying mechanism is still unclear. In this study, the metabolic profiling of $D$. salina cells during the process of nitrogen deprivation was performed by gas chromatography-mass spectrometry. A total of 78 metabolites were identified and quantified, including 16 amino acids, 19 sugars, 13 organic acids, 11 alcohols, 11 fatty acids, 4 amines and 4 others. Nitrogen deprivation induced changes in saturation of fatty acids by increasing saturated fatty acids and decreasing polyunsaturated fatty acids in $D$. salina. The relative levels of metabolites such as sucrose, maltose and organic acids, which act as carbon skeleton, were increased, in contrast, glycerol, myo-inositol which are related to the osmoregulatory mechanism, kept constant under nitrogen deprivation condition. The levels of proline, glutamic acid and other metabolites, which were involved in protective function, were increased in nitrogen deprivation condition. The precursors of these metabolites are the intermediates of the Calvin cycle and the TCA cycle. The results of this research might be applicable to the interpretation of metabolic synthesis and fatty acid production during process of nitrogen deprivation and provide a new method for accumulating high amounts of carotenoids in $D$. salina.
\end{abstract}

Keywords: Dunaliella salina; Nitrogen deprivation; Gas chromatography-mass spectrometry; Metabolomics; Fatty acids

\section{Abbreviations}

GC-MS: Gas Chromatography-Mass Spectrometry; NIST: National Institute of Standards and Technology; PCA: Principal Component Analysis; PLS: Partial Least-Squares; FAMEs: Fatty Acid Methyl Esters; LSD: Least Significant Difference Test; SFA: Saturated Fatty Acids; USFA: Unsaturated Fatty Acids;MUFA: Monounsaturated Fatty Acids; PUFA: Polyunsaturated Fatty Acids

\section{Introduction}

The unicellular microalga $D$. salina is one of the richest sources of natural-carotene. It can withstand extremely harsh environments such as high light intensities, high salinities, and nutrients stress [1-3]. It can accumulate high amount of $\beta$-carotene which is more than $14 \%$ of its dry weight in its cup shaped chloroplast when subjected to abiotic stresses [4]. Most of the accumulated $\beta$-carotene is concentrated in intrachloroplastic lipoidal globules. Nowadays, it is widely believed that $D$. salina is the best commercial source of natural $\beta$-carotene among all organisms in the world [2,5-7].

Carotenoids are employed in the food, cosmetic and pharmaceutical industries as colorant, antioxidant and anti-cancer agent. Natural carotenoids produced by D. salina contain about $50 \%$ all-trans $\beta$-carotene with the rest composed mostly of cis- $\beta$-carotenes and minor amounts of a few other di-cis- $\beta$-carotene isomer. These compounds have antioxidant properties and have attracted attention as potential agent in prevention of cancers, which is superior to the artificially synthesized all-trans- $\beta$-carotene with a high ratio of 9 -cis form to all-trans form [8-10]. Although $D$. salina is a good candidate of natural $\beta$-carotene source, their commercial application is still limited because of low productivity of the culture [11]. Nitrogen is an essential macronutrient for all organisms, and is widely used in biochemical processes. Nitrogen deprivation is one of the most potent environmental factors inducing $\beta$-carotene accumulation in $D$. salina [12]. However, little is known about the underlying regulatory mechanisms of the metabolic response to nitrogen deprivation. So far, there have been no reports on changes in metabolic profiles and FA production upon shifting to nitrogen deprivation conditions. In this study, the metabolomics of $D$. salina upon nitrogen deprivation were performed. Our results showed that cell growth, metabolite profiles, and FA production were altered during the process of nitrogen deprivation. The results, based on comprehensive metabolomics studies, might be applicable for optimizing culture conditions in D. salina or other microalgal systems for the production of biofuel and carotenoids or valuable compounds.

\section{Materials and Method}

\section{Algae and cultivation conditions}

D. salina cultured in the modified Johnson's medium [13] containing the following components: $\mathrm{NaCl} 60 \mathrm{~g} / \mathrm{L}, \mathrm{MgCl}_{2} \cdot 7 \mathrm{H}_{2} \mathrm{O} 1.38$ $\mathrm{g} / \mathrm{L}, \mathrm{MgSO}_{4} \cdot 7 \mathrm{H}_{2} \mathrm{O} 0.5 \mathrm{~g} / \mathrm{L}, \mathrm{KCl} 0.2 \mathrm{~g} / \mathrm{L}, \mathrm{CaCl}_{2} 0.035 \mathrm{~g} / \mathrm{L}, \mathrm{KNO}_{3} 0.5 \mathrm{~g} / \mathrm{L}$, $\mathrm{NaHCO}_{3} 0.151 \mathrm{~g} / \mathrm{L}, \mathrm{KH}_{2} \mathrm{PO}_{4} 0.043 \mathrm{~g} / \mathrm{L}, \mathrm{Na}_{2}$ EDTA.2 $\mathrm{H}_{2} \mathrm{O} 2.09 \mathrm{mg} / \mathrm{L}$, $\mathrm{FeCl}_{3} \cdot 6 \mathrm{H}_{2} \mathrm{O} 2.44 \mathrm{mg} / \mathrm{L}, \mathrm{ZnCl}_{2} 41 \mu \mathrm{g} / \mathrm{L}, \mathrm{H}_{3} \mathrm{BO}_{3} 0.61 \mathrm{mg} / \mathrm{L}, \mathrm{CoCl}_{2} \cdot 6 \mathrm{H}_{2} \mathrm{O}$ $51 \mu \mathrm{g} / \mathrm{L}, \mathrm{CuSO}_{4} \cdot 5 \mathrm{H}_{2} \mathrm{O} 60 \mu \mathrm{g} / \mathrm{L}, \mathrm{MnCl}_{2} \cdot 4 \mathrm{H}_{2} \mathrm{O} 41 \mu \mathrm{g} / \mathrm{L},\left(\mathrm{NH}_{4}\right)_{6} \mathrm{Mo}_{7} \mathrm{O}_{24}$.

*Corresponding author: Lv H, Tianjin Key Laboratory of Marine Resources and Chemistry, Tianjin University of Science and Technology, Tianjin, 300457, P.R. China, E-mail: Ivhx@tust.edu.cn and

Jia S, Key Laboratory of Industrial Fermentation Microbiology, Ministry of Education, Tianjin Key Lab of Industrial Microbiology, Tianjin University of Science and Technology, Tianjin, 300457, P.R. China, Tel: +86-22-60601598; Fax: 86-2260602298; E-mail: jiashiru@tust.edu.cn

Received January 29, 2016; Accepted February 18, 2016; Published February 20, 2016

Citation: Lv H, Cui X, Wang S, Jia S, (2016) Metabolic Profiling of Dunaliella salina Shifting Cultivation Conditions to Nitrogen Deprivation. Metabolomics 6: 170 doi:10.4172/2153-0769.1000170

Copyright: @ 2016 Lv H, et al. This is an open-access article distributed under the terms of the Creative Commons Attribution License, which permits unrestricted use, distribution, and reproduction in any medium, provided the original author and source are credited. 
$4 \mathrm{H}_{2} \mathrm{O} 0.38 \mathrm{mg} / \mathrm{L}$. Cells were batch-cultured in $500 \mathrm{~mL}$ Erlenmeyer flasks containing $250 \mathrm{~mL}$ of medium under continuous illumination (60 $\mu \mathrm{mol} \cdot \mathrm{m}^{-2} \cdot \mathrm{s}^{-1}$, fluorescent lamp, $400-700 \mathrm{~nm}$ ), and the temperature was $30.0 \pm 1.0^{\circ} \mathrm{C}$. Cells were inoculated at $2.0 \times 10^{5} \mathrm{cell} / \mathrm{ml}$. Cultures were manually shaken three times a day. All the cells were cultured for two 16/8 hour light/dark cycles to synchronize the growth phases before inoculation and thereafter transfer to continuous light conditions. For experiments performed under nitrogen deprivation, cells in the late exponential growth phase (the seventh day after nitrogen deprivation) were collected by centrifugation at $4,000 \mathrm{rpm}$ for $5 \mathrm{~min}$ and resuspended in the same volume of the growth medium without nitrate for 3 times.

\section{Cell density determination}

Cell counts were performed every 2 days using haemacytometer. The cells were fixed by glutaraldehyde $(0.25 \%$ final concentration $)$ for 2 min, then counted by optical microscope (Olympus CX40, Japan) and haemacytometer for more than 3 times. All data in this study were processes by Origin 9.0.0 (OriginLab), statistical significance analyses were performed by SPSS v19.0 (IBM). One-way ANOVA followed by the Least Significant Difference Test (LSD) in the post hoc analysis was used in this study.

\section{Extraction of intracellular metabolites}

The quenching and extraction processes were performed according to previously described method [14] with some modifications. In detail, samples were immediately quenched with pre-chilled $-40^{\circ} \mathrm{C} 60 \%(\mathrm{v} / \mathrm{v}$, methanol/water) methanol solution for $5 \mathrm{~min}$. Cells were collected by centrifugation at $4,000 \mathrm{rpm}$ for $5 \mathrm{~min}$ at $4^{\circ} \mathrm{C}$ and washed with sodium chloride solution $(0.5 \mathrm{~mol} / \mathrm{L})$ thirdly. The cell pellets were immediately frozen in liquid nitrogen and ground into powder. The intracellular metabolites were extracted according to previously reported methods $[15,16]$. Briefly, $50 \mathrm{mg}$ cell powder was suspended in $1 \mathrm{~mL}$ of prechilled $\left(-20^{\circ} \mathrm{C}\right)$ extraction solution (methanol/water, $\left.1: 1, \mathrm{v} / \mathrm{v}\right)$ and 5 $\mu \mathrm{L}$ of internal standard solution (succinic acid, 2,2,3,3-d4, $1.5 \mathrm{mg} / \mathrm{mL}$, Sigma, USA), then thoroughly mixed by vortexing. The mixture was frozen in liquid nitrogen for $2 \mathrm{~min}$ and then thawed, and the cycle was repeated for five times. The supernatant was collected by centrifugation at 10,000 rpm for $5 \mathrm{~min}$ and was then used for lyophilization.

\section{Derivatization and GC-MS analysis}

Prior to GC-MS analysis, a two-step chemical derivatization was performed. Firstly, $50 \mu \mathrm{L}$ of methoxamine hydrochloride $(20 \mathrm{mg} /$ $\mathrm{mL}$ in pyridine, Sigma, USA) was added to the lyophilizate, and the mixture was incubated at $40^{\circ} \mathrm{C}$ for $80 \mathrm{~min}$. Then, $80 \mu \mathrm{L}$ of N-methyl-N(trimethylsilyl) trifluoroacetamide (MSTFA, Sigma) was added to the samples, also incubated at $40^{\circ} \mathrm{C}$ for $80 \mathrm{~min}$. At last, the samples were placed at room temperature for 2 hours.

GC-MS analysis was performed by using a GC-MS system (Agilent 7890 GC-5975 MSC, USA) equipped with a HP-5 capillary column $(60 \mathrm{~m} \times 320 \mu \mathrm{m}$ i.d., $0.25 \mu \mathrm{m}$ film thickness; Agilent JandW Scientific, Folsom, CA, USA). $1 \mu \mathrm{L}$ of sample was injected without a split ratio. Helium was used as the carrier gas at a constant flow rate of $1 \mathrm{~mL} / \mathrm{min}$. The electron impact ionization $(70 \mathrm{eV})$ was set to full scan mode $(\mathrm{m} / \mathrm{z}$ : 50-800). The GC oven temperature for metabolomics was set to $70^{\circ} \mathrm{C}$ for $2 \mathrm{~min}$, then raised to $290^{\circ} \mathrm{C}$ at a rate of $5^{\circ} \mathrm{C} / \mathrm{min}$, and maintained at $290^{\circ} \mathrm{C}$ for $6 \mathrm{~min}$. The GC oven temperature for fatty acid methyl esters analysis was set to $70^{\circ} \mathrm{C}$ for $2 \mathrm{~min}$, followed by an increasing rate of $8^{\circ} \mathrm{C} / \mathrm{min}$ to $200^{\circ} \mathrm{C}$, which was held for $2 \mathrm{~min}$, then increased at a rate $3^{\circ} \mathrm{C} / \mathrm{min}$ to $245^{\circ} \mathrm{C}$ and maintained at $245^{\circ} \mathrm{C}$ for $6 \mathrm{~min}$.

\section{Extraction of fatty acid methyl esters}

The fatty acids were extracted according to a modified method [17]. Briefly, $10 \mathrm{mg}$ algae powder was suspended in $0.8 \mathrm{~mL}$ fatty acid extract (Trichloromethane:methanol, 2:1, v:v) and $10 \mu \mathrm{L}(80 \mu \mathrm{g} / \mathrm{mL})$ nonadecanoic acid (internal standard solution) was added and mixed thoroughly, and added $1.2 \mathrm{~mL}$ FAMES reagent (10\% $\mathrm{HCl}$-methanol, $\mathrm{m}: \mathrm{m}$ ) into the samples. The mixture was incubated at $80^{\circ} \mathrm{C}$ for 1 hour. Fatty acid methyl esters were extracted with $1 \mathrm{~mL}$ hexane and vortexed for $2 \mathrm{~min}$. After centrifuge at $10000 \mathrm{rpm}$ for $5 \mathrm{~min}$, the hexane phase was used for further GC-MS analysis.

\section{Data analysis and statistical analysis of GC-MS}

Typical total ion chromatograms (TIC) of the D. salina cells were obtained by GC-MS. The MSD Productivity ChemStation software (version E.02.01.1177 Agilent) was used for data analyses. The National Institute of Standards and Technology (NIST) mass spectral library 2011 (version $2.0 \mathrm{~g}$ ) were used for metabolite identification. Unsupervised principal component analysis (PCA) was used for initial analysis. Supervised partial least-squares (PLS) analysis was used to further verify the differences and identify the metabolites responsible for distinguishing the three different growth phases. Both supervised PLS and unsupervised PCA were performed by SIMCA package (ver. 11.5) (Umetrics, Umea, Sweden). Score plots of PLS and PCA were used to previewing the clustering effect. Loading plots of PCA and PLS were used for finding biomarkers. The relative contents of metabolites and fatty acids were calculated according to a previous method [18].

\section{Results and Discussion}

\section{Effects of nitrogen deprivation on cell growth}

Figure 1 shows the cell density of $D$. salina cells under nitrogen deprivation and complete medium (CM) conditions. The growth of cells was partially inhibited during in three day after inoculation and then decreased gradually under $-\mathrm{N}$ condition. The contents of total carotenoids and $\beta$-carotene were gradually increased and reached 4.77 and $3.61 \mathrm{pg}$ per cell, respectively, along with the extension of nitrogen deprivation. In contrast, the cells under CM condition could keep growing for 13 days and the contents of total carotenoids $(2.29 \mathrm{pg}$ per cell) and $\beta$-carotene $(0.8783 \mathrm{pg}$ per cell) were constant, and in the end of the cultivation, the density of cells was 10 -fold than those cultured

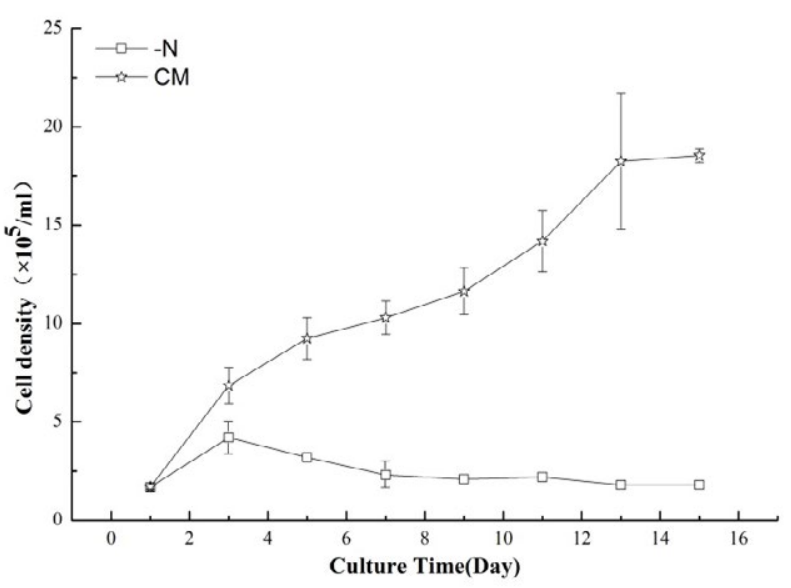

Figure 1: The effects of nitrogen deprivation on the cell growth of $D$. salina. Cell density was determined for 15 days after exposure to the different treatments. Plotted data are the averages \pm SD of six replicates. 
in - $\mathrm{N}$ condition. These results indicated that the growth of cells was inhibited $(\mathrm{P}<0.001)$ and carotenoids metabolism $(\mathrm{P}<0.001)$ were activated by nitrogen deprivation.

\section{Effects of altered conditions on D. salina FA profiles}

In this study, a total of $15 \mathrm{FAs}$ were identified from D. salina under $\mathrm{CM}$ and $-\mathrm{N}$ conditions, including 3 saturated fatty acids (SFA) and 12 unsaturated fatty acids (UFA). The total amount of cellular lipid was significantly higher $(\mathrm{P}<0.001)$ under $-\mathrm{N}$ condition than those under CM condition. Some FAs only were identified in CM condition, e.g. 10-octadecenoic acid (18:1), 10, 13-eicosadienoic acid (20:2), 5,8,11,14-eicosatetraenoic acid (20:4). The major FA components were 9,12,15-octadecatrienoic acid (C18:3) (35\%-38\%), hexadecanoic acid (C16:0) (22\%-27\%). This FAs composition was similar to previous reports $[17,19-21]$.

There were differences in the composition of saturated fatty acids (SFAs), monounsaturated fatty acids (MUFAs), and polyunsaturated fatty acids (PUFAs) when D. salina cells were cultivated under different conditions. Under -N condition, the levels of SFAs, especially C16:0, and the levels of PUFAs, including C18:2, C18:3, and C22:3, were higher, and MUFAs were lower than those under CM condition. The C18:1 fatty acid was not detected in cells under $-\mathrm{N}$ condition. PUFAs play key roles in many biological functions including regulating membrane fluidity, oxygen and electron transport as well as thermal adaptation in cellular metabolism [22,23]. Therefore, the changes in PUFAs under $-\mathrm{N}$ condition is not surprising. The total FA of cells under $-\mathrm{N}$ condition was significantly increased compared to those under $\mathrm{CM}$ condition ( $\mathrm{P}$ $<0.001)$. It was reported that nitrogen deprivation can induce increases in lipid content in D. viridis and D. tertiolecta [24-26], but can have no effect on lipid content of the cells of $D$. salina [1], the possible reason for the inconsistence were sampling time and the difference of light intensity used in cultivation.

Altogether, nitrogen deprivation of $D$. salina cells led to a decreased degree of UFAs $(\mathrm{P}<0.001)$. This reduction in the degree of unsaturation was similar with previous report [12] and we also observed the trend correlated negatively with the intracellular content of total carotenoids and $\beta$-carotene. PUSAs are particularly sensitive to oxidation and the observed specific loss of unsaturated fatty acids upon nitrogen deprivation thus may implicate oxidative stresses occurred in cells [12]. Since $\beta$-carotene accumulation requires de novo synthesis of fatty acids for the formation of lipid globules [27], the increased levels of saturated and total fatty acids might reflect de novo synthesis of triacylglycerol molecules occurred within the lipid globules.

\section{Effects of nitrogen deprivation on intracellular metabolites of D. salina}

To investigate the effect of nitrogen deprivation on intracellular metabolites of $D$. salina, the metabolites were extracted by methanol and water, and analyzed by GC-MS. In the total ion chromatogram, more than 250 chromatographic peaks were detected in each sample. To screen for valid metabolites, the initial GC peak width and initial threshold were set to 0.1 and 15.0, respectively. By comparing with the NIST library and filtering for match degrees greater than 700 , seventyeight metabolites could be assigned to the detected peaks, including 16 amino acids, 19 sugars, 13 organic acids, 11 lipids, 11 alcohols, 4 amine and 4 others (Table 1). The intensities of the majority of these metabolites undergo marked changes by shifting conditions to $-\mathrm{N}$. To study changes in the intracellular metabolites, multivariate statistical analysis was performed by PCA and PLS. The results show that both models were well constructed with excellent fit and satisfactory predictive ability. The unsupervised clustering method PCA was used to identify and rank major metabolites of variance within the two data sets. Based on similarities and differences in the measured parameters, PCA was able to cluster biological samples into both expected and unexpected groups. Samples in -N and CM conditions were separated clearly on the PCA and PLS score plot (Figures 2A-2D), and different repetitions of the same sample could be clustered together closely. In PCA analysis, the first principal component (PC1) accounted for $93.3 \%$ of the total variance among the two different conditions. The PC1 and PC2 (these two components account for $99.1 \%$ of the variance) could explain the different of the two conditions, which showed that the intracellular metabolites of $D$. salina differed faced to shifting conditions. The supervised clustering method PLS was used to further validate the differences between the two conditions. The results of PLS were similar to that of PCA, and further validated the differences between two cultivation conditions.

In the score plots, the confidence interval is defined by Hotelling's T2 ellipse (95\% confidence interval), and observations outside the confidence ellipse are considered outliers. The relative intensity of each metabolite peak is expressed as the ratio of the peak area to that of the internal standard. Normalized peak areas were imported into SIMCA-P for multivariate statistical analysis.

The loading plots of PCA and PLS were used to analyze the contribution of each metabolite to the principal components, and selected the main biomarkers from metabolites. The result showed that the potential biomarkers identified by PCA loading plots were sucrose, glycerol, octadecanoic acid, hexadecanoic acid, 13-docosenoic acid, lactic acid, 11-eicosenoic acid, cadaverine, $\alpha$-ketoglutaric acid and 9-Octadecenoic acid. The potential biomarkers identified by PLS were similar to PCA. The VIP coefficients reflect the contribution of each metabolite to the PLS models. A higher VIP value shows that the metabolite has a larger contribution (Figure 3). Finally, six potential biomarkers that made relatively high contributions to both the PCA and PLS loading plots were identified: 13-docosenoic acid, sucrose, lactic acid, 9-Octadecenoic acid, hexadecanoic acid, octadecanoic acid, 11 -eicosenoic acid and $\alpha$-ketoglutaric acid.

It was reported that nitrogen starvation leads to a reduction of de novo amino acid biosynthesis [28], however, our results showed that the contents of leucine, threonine, ornithine, proline and glutamic acid were increased. On the other hand, the levels of maltose and sucrose were increased, while the levels of glycerol and myo-inositol had no significant changes between -N and CM conditions. This result is consistent with the truth of constant salinities between the two culturing conditions $[29,30]$. Sucrose and maltose is the major product of photosynthesis in plants, and play important roles in carbohydrate storage and stress responses [31]. Our results showed that cells prefer to synthesize metabolites without nitrogen, e.g. sugars, organic acids (Figure 4A), fatty acids (Table 2) when subjected to nutrients deprivation, especially nitrogen deprivation.

Many plants when were subjected to stresses can accumulate high levels of proline and glutamic acid. Proline and glutamic acid can stabilize the cell membrane structure, scavenge free radicals, and can be used as nitrogen and carbon frame also provide the energy for plants [32-34]. Besides those two amino acids, ornithine generating from urea cycle plays an important role in the metabolism of organisms, and is the substrate of arginine and citrulline and so on. Citrulline also is 

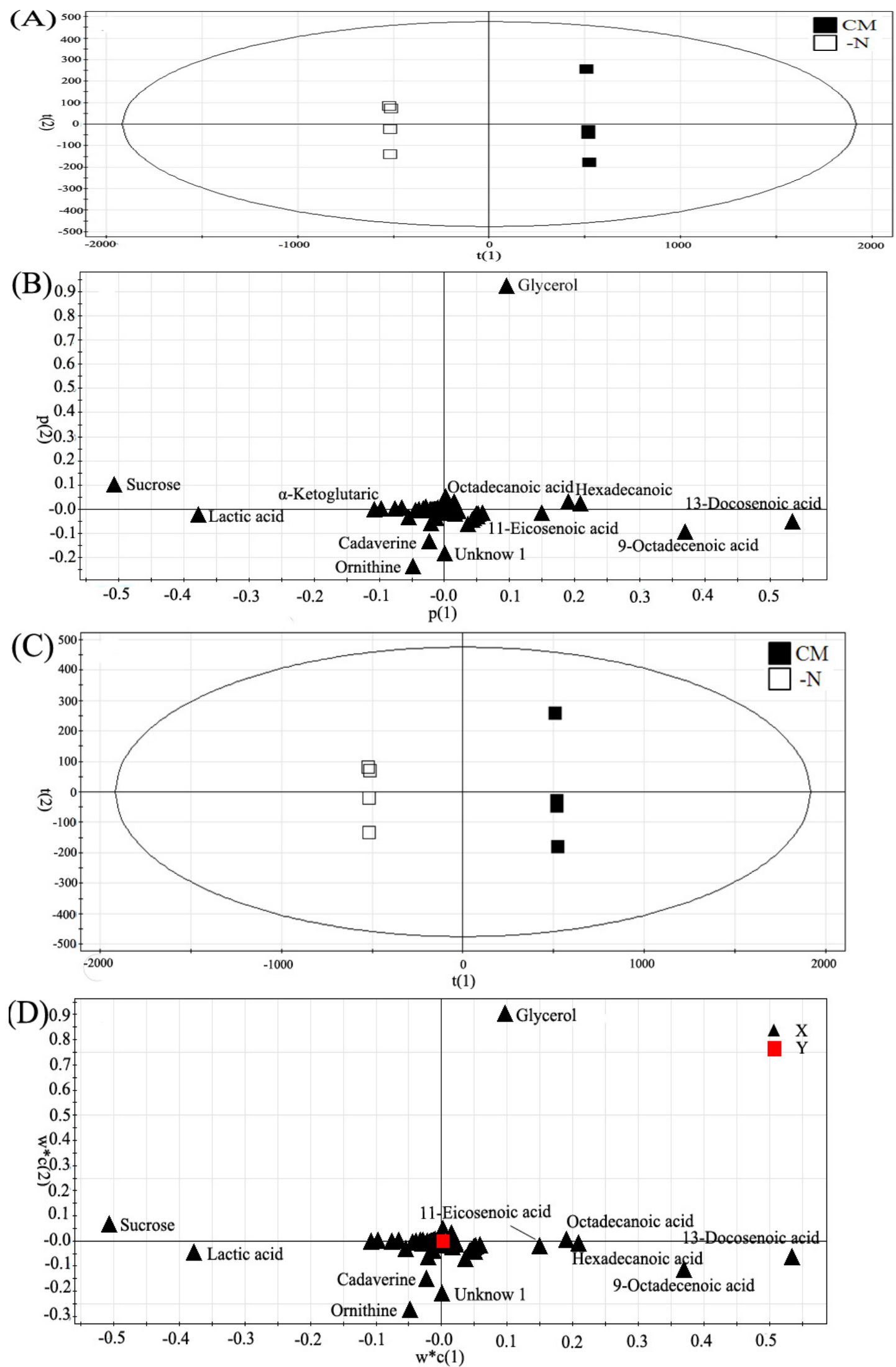

Figure 2: PCA score plot (A), PCA loading plot (B), PLS score plot (C) and PCA loading plot (D) for samples from $D$. salina in two conditions 
Citation: Lv H, Cui X, Wang S, Jia S, (2016) Metabolic Profiling of Dunaliella salina Shifting Cultivation Conditions to Nitrogen Deprivation. Metabolomics 6: 170. doi:10.4172/2153-0769.1000170

Page 5 of 9

\begin{tabular}{|c|c|c|c|}
\hline \multirow[t]{2}{*}{ Class } & \multirow[t]{2}{*}{ Components } & \multicolumn{2}{|c|}{ Cultivation Conditions } \\
\hline & & $-\mathrm{N}$ & $\mathrm{CM}$ \\
\hline \multirow[t]{16}{*}{ Amino acids } & $\mathrm{N}, \mathrm{N}$-Dimethylglycine & $10.13 \pm 2.15$ & $26.39 \pm 7.43$ \\
\hline & Valine & $8.04 \pm 1.37$ & $9.26 \pm 1.37$ \\
\hline & Alanine & $10.22 \pm 0.86$ & $27.38 \pm 5.11$ \\
\hline & Leucine & $12.24 \pm 0.33$ & $4.74 \pm 0.98$ \\
\hline & Isoleucine & $2.47 \pm 0.23$ & $3.31 \pm 0.30$ \\
\hline & Norvaline & $3.60 \pm 0.44$ & $7.19 \pm 0.48$ \\
\hline & Serine & $24.38 \pm 0.77$ & $34.38 \pm 2.15$ \\
\hline & Threonine & $25.67 \pm 0.44$ & $17.50 \pm 1.31$ \\
\hline & Serine & $9.07 \pm 0.89$ & $16.70 \pm 4.89$ \\
\hline & $\mathrm{N}, \mathrm{O}, \mathrm{O}-\mathrm{Tris}$ (trimethylsilyl)-L-threonine & $7.01 \pm 0.55$ & $6.17 \pm 1.00$ \\
\hline & Ornithine & $356.86 \pm 11.19$ & $306.86 \pm 56.10$ \\
\hline & N- $\alpha$-Acetyl-L-Lysine & $17.55 \pm 1.49$ & $7.85 \pm 0.73$ \\
\hline & Proline & $160.15 \pm 14.51$ & $103.07 \pm 22.19$ \\
\hline & Glycyl-I-glutamic acid & $115.00 \pm 10.56$ & $117.29 \pm 18.80$ \\
\hline & Glutamic acid & $44.60 \pm 13.47$ & $23.96 \pm 9.98$ \\
\hline & Lysine & N.D. & $37.36 \pm 15.17$ \\
\hline \multirow[t]{19}{*}{ Sugars } & Erythrose & $21.87 \pm 0.84$ & N.D. \\
\hline & Trehalose & $16.70 \pm 0.40$ & $13.25 \pm 1.61$ \\
\hline & Ribose & $5.08 \pm 0.35$ & $13.23 \pm 2.11$ \\
\hline & Tagatose & $6.91 \pm 0.10$ & N.D. \\
\hline & Sorbose & $10.39 \pm 0.24$ & N.D. \\
\hline & Fructose & $6.55 \pm 0.05$ & N.D. \\
\hline & Galactose & $14.38 \pm 0.23$ & $28.70 \pm 3.34$ \\
\hline & Talose & $14.64 \pm 0.29$ & $10.90 \pm 0.27$ \\
\hline & Mannose & $5.23 \pm 0.26$ & N.D. \\
\hline & Glucose & $18.19 \pm 1.49$ & $7.80 \pm 0.94$ \\
\hline & 2-Deoxy-D-ribose & $45.35 \pm 1.48$ & N.D. \\
\hline & Erythro-Pentose & $2.97 \pm 0.26$ & $53.94 \pm 5.19$ \\
\hline & erythro-2-Pentulose & $100.32 \pm 3.18$ & N.D. \\
\hline & Maltose & $11.08 \pm 0.97$ & N.D. \\
\hline & Lactose & $22.79 \pm 1.83$ & $42.99 \pm 1.00$ \\
\hline & Fructose & $33.90 \pm 2.38$ & N.D. \\
\hline & Mannose & $94.11 \pm 5.73$ & $26.40 \pm 0.94$ \\
\hline & Sucrose & $747.27 \pm 41.04$ & $222.32 \pm 14.67$ \\
\hline & Cellobiose & $22.46 \pm 1.57$ & $2.52 \pm 0.46$ \\
\hline \multirow[t]{11}{*}{ Fatty Acids } & Nonanoic acid & N.D. & $15.45 \pm 2.00$ \\
\hline & Dodecanoic acid & N.D. & $4.37 \pm 0.22$ \\
\hline & Hexadecanoic acid & $412.85 \pm 20.72$ & $629.58 \pm 12.80$ \\
\hline & 9-Octadecenoic acid & N.D. & $382.06 \pm 35.98$ \\
\hline & Tetradecanoic acid & $29.88 \pm 4.66$ & N.D. \\
\hline & 11-Eicosenoic acid & N.D. & $154.40 \pm 8.37$ \\
\hline & 13-Eicosenoic acid & N.D. & $60.39 \pm 4.14$ \\
\hline & Decanoic acid & N.D. & $4.03 \pm 0.29$ \\
\hline & 13-Docosenoic acid & N.D. & $553.77 \pm 29.78$ \\
\hline & Docosanoic acid & N.D. & $54.09 \pm 4.96$ \\
\hline & Octadecanoic acid & $360.81 \pm 19.35$ & $558.26 \pm 11.98$ \\
\hline
\end{tabular}


Citation: Lv H, Cui X, Wang S, Jia S, (2016) Metabolic Profiling of Dunaliella salina Shifting Cultivation Conditions to Nitrogen Deprivation. Metabolomics 6: 170. doi:10.4172/2153-0769.1000170

Page 6 of 9

\begin{tabular}{|c|c|c|c|}
\hline \multirow{13}{*}{ Oganic acid } & Lactic acid & $532.74 \pm 12.16$ & $141.92 \pm 17.13$ \\
\hline & Acetic acid & $5.74 \pm 0.41$ & $5.04 \pm 0.28$ \\
\hline & Ethanedioic acid & $299.52 \pm 7.51$ & $351.87 \pm 15.17$ \\
\hline & 2,3,4-Trihydroxybutyric acid & $7.97 \pm 0.94$ & $7.48 \pm 0.29$ \\
\hline & Pentanedioic acid & $40.03 \pm 0.56$ & $25.38 \pm 0.74$ \\
\hline & Phosphoric acid & $115.16 \pm 3.44$ & $36.32 \pm 1.16$ \\
\hline & Azelaic acid & $9.74 \pm 3.47$ & $56.63 \pm 7.57$ \\
\hline & Propanoic acid & $67.39 \pm 3.01$ & $90.56 \pm 6.25$ \\
\hline & a-Ketoglutaric acid & $156.81 \pm 2.51$ & $45.21 \pm 2.36$ \\
\hline & Sebacic acid & N.D. & $20.99 \pm 0.71$ \\
\hline & Butanoic acid & $4.83 \pm 0.32$ & N.D. \\
\hline & Deoxycholic acid & $4.30 \pm 0.22$ & $6.64 \pm 1.14$ \\
\hline & L-Ascorbic acid & $22.03 \pm 1.70$ & $10.81 \pm 2.24$ \\
\hline \multirow[t]{11}{*}{ Alcohols } & Glycerol & $2596.94 \pm 70.61$ & $2697.75 \pm 249.25$ \\
\hline & Pentitol & $19.19 \pm 0.19$ & $18.15 \pm 1.26$ \\
\hline & Erythro-Pentitol & $14.49 \pm 0.95$ & $13.53 \pm 1.41$ \\
\hline & Arabitol & $13.64 \pm 0.29$ & $15.74 \pm 1.45$ \\
\hline & Xylitol & $14.61 \pm 0.28$ & $9.93 \pm 0.15$ \\
\hline & Adonitol & $59.65 \pm 0.76$ & $46.88 \pm 8.74$ \\
\hline & Fucitol & $3.81 \pm 0.16$ & N.D. \\
\hline & Mannitol & N.D. & $19.25 \pm 0.46$ \\
\hline & Sorbitol & N.D. & $4.91 \pm 0.42$ \\
\hline & Myo-Inositol & $28.48 \pm 0.50$ & $28.14 \pm 3.52$ \\
\hline & meso-Erythritol & $49.13 \pm 0.49$ & $36.83 \pm 0.32$ \\
\hline \multirow[t]{4}{*}{ Amines } & Acetamide & $35.39 \pm 4.85$ & $79.16 \pm 16.48$ \\
\hline & Cadaverine & $185.69 \pm 8.06$ & $161.49 \pm 30.91$ \\
\hline & 3-methylol-methylamine & $40.97 \pm 0.37$ & $24.46 \pm 0.32$ \\
\hline & Urea & $3.81 \pm 0.89$ & $5.98 \pm 0.68$ \\
\hline \multirow[t]{4}{*}{ Others } & Unknown 1 & $187.36 \pm 10.61$ & $188.11 \pm 45.62$ \\
\hline & Unknown2 & $30.31 \pm 1.96$ & N.D. \\
\hline & Unknown3 & $12.83 \pm 0.15$ & $16.03 \pm 0.94$ \\
\hline & Unknown 4 & $39.70 \pm 0.51$ & N.D. \\
\hline
\end{tabular}

Table 1: Metabolites of $D$. salina cultivated under different conditions. Data are shown as the mean \pm SD values for 4 measurements. N.D, Not Detected.

a scavenger of oxygen free radicals. Consistent with previous report [32-34], the three amino acids of cells under $-\mathrm{N}$ condition were also increased in our study. Similarly, the monosaccharides with protective function were increased in cells under $-\mathrm{N}$ condition, e.g. trehalose, talose, sorbose (Figure 4B).

It has been reported that the contents of amino acids of cells are directly related to their metabolic precursors and alanine, pyruvic acid is precursor of valine, leucine and isoleucine $[35,36]$. In the present study, synthetic precursors of most of the detected amino acids are the intermediates of the Calvin cycle and the TCA cycle. Alanine, valine, isoleucine in cells under $-\mathrm{N}$ condition were reduced to $37.3 \%$, 87.5\% and $75.2 \%$ compared to those under CM condition (Figure 5 ). The precursor of proline and glutamic acid is a-ketoglutarate, which is also an important intermediate of the TCA cycle. The level of a-ketoglutarate in cells under - $\mathrm{N}$ condition was 3.5 -fold increase compared to those under CM condition. Therefore, increased levels of sucrose and ornithine implicated that the metabolic intermediates of the Calvin cycle and urea cycle were increased.

\section{Conclusion}

In this study, the saturation of FAs was higher under $-\mathrm{N}$ condition, and was caused by significant decreases in UFAs and increases in SFAs in D. salina cells. A total of 79 metabolites were identified and quantified through GC-MS in $-\mathrm{N}$ and CM conditions. In different cultivation conditions, the intracellular metabolisms of D. salina were changed significantly (Figure 6). The relative levels of metabolites acting as ergastic substances, such as sucrose, maltose, were significantly increased by $-\mathrm{N}$ shifts. When nitrogen limited, the metabolic intermediates of the Calvin cycle, part of TCA cycle and urea cycle were significantly increased. The cells of $D$. salina preferred to synthesis metabolites without nitrogen e.g. organic acid and fatty acids rather than the amino acids, but many metabolites such as proline and glutamic acid with protective function were increased. Future studies will be performed to investigate the mechanisms of metabolites and FA profiles using multi-omics approaches, such as genomics, transcriptomics, proteomics, and metabolomics in different nutrient deprivations, e.g. phosphorus and sulfur. 
Citation: Lv H, Cui X, Wang S, Jia S, (2016) Metabolic Profiling of Dunaliella salina Shifting Cultivation Conditions to Nitrogen Deprivation. Metabolomics 6: 170. doi:10.4172/2153-0769.1000170

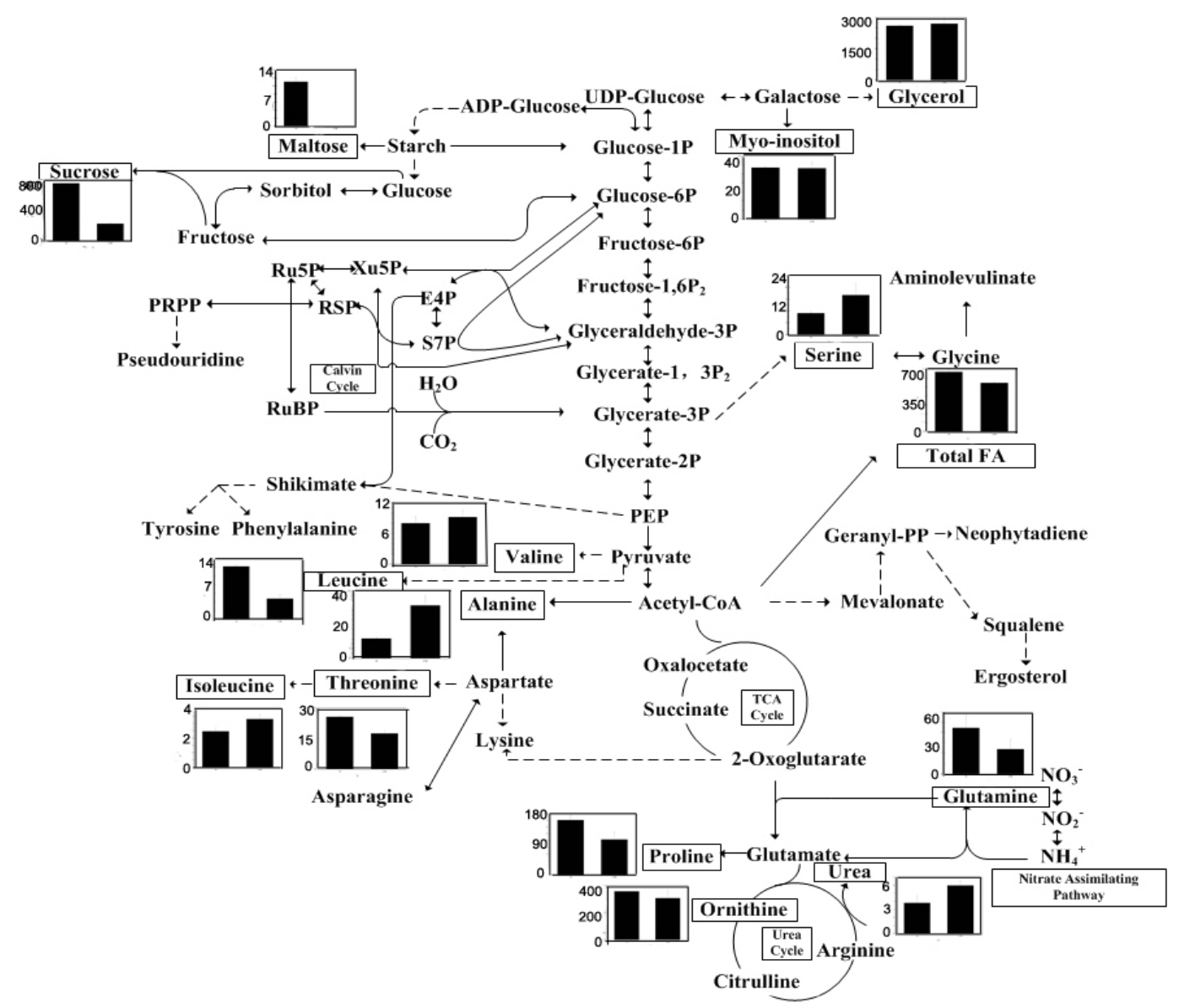

Figure 3: Diagram showing changes in metabolite abundance mapped onto the metabolic network, including the Calvin cycle, the TCA cycle, amino acid metabolic pathway and other pathways. The left of each column diagram is $-\mathrm{N}$ condition, the right is $\mathrm{CM}$ condition.

\begin{tabular}{|c|c|c|c|}
\hline \multirow[t]{2}{*}{ FA } & \multirow[t]{2}{*}{ Cx:y } & \multicolumn{2}{|c|}{ D. salina based FA composition (\%) } \\
\hline & & $-\mathrm{N}$ & $\mathrm{CM}$ \\
\hline Tridecanoic acid & $(13: 0)$ & $0.65 \pm 0.02$ & $0.45 \pm 0.02$ \\
\hline Hexadecanoic acid & $(16: 0)$ & $27.71 \pm 0.39$ & $22.96 \pm 0.39$ \\
\hline Heptadecanoic acid & $(17: 0)$ & $0.82 \pm 0.17$ & $0.81 \pm 0.09$ \\
\hline$\sum$ SFA & & $29.19 \pm 0.59$ & $24.23 \pm 0.50$ \\
\hline 9-Hexadecenoic acid & $(16: 1)$ & $1.83 \pm 0.34$ & $2.28 \pm 0.04$ \\
\hline 10-Octadecenoic acid & $(18: 1)$ & N.D. & $0.17 \pm 0.04$ \\
\hline$\sum$ MUFA & & $1.83 \pm 0.34$ & $2.45 \pm 0.08$ \\
\hline 7,10-Hexadecadienoic acid & $(16: 2)$ & $3.08 \pm 0.11$ & $3.45 \pm 0.09$ \\
\hline 7,10-Octadecadienoic acid & $(18: 2)$ & $0.96 \pm 0.03$ & $0.85 \pm 0.23$ \\
\hline 9,12-Octadecadienoic acid & $(18: 2)$ & $12.30 \pm 0.14$ & $11.47 \pm 0.07$ \\
\hline 10,13-Eicosadienoic acid & $(20: 2)$ & N.D. & $0.22 \pm 0.01$ \\
\hline Y-Linolenic acid & $(16: 3)$ & $1.22 \pm 0.05$ & $1.22 \pm 0.34$ \\
\hline $9,12,15$-Octadecatrienoic acid & $(18: 3)$ & $38.10 \pm 1.06$ & $35.43 \pm 0.36$ \\
\hline cis-5,8,11-Eicosatrienoic acid & $(20: 3)$ & $3.19 \pm 0.24$ & $3.87 \pm 0.06$ \\
\hline 5,8,11,14-Eicosatetraenoic acid & $(20: 4)$ & N.D. & $3.65 \pm 0.14$ \\
\hline 6,9,12,15-Docosatetraenoic acid & $(22: 4)$ & $0.93 \pm 0.15$ & $0.75 \pm 0.04$ \\
\hline $4,7,10,13,16,19-D o c o s a h e x a e n o i c ~ a c i d ~$ & $(22: 6)$ & $9.19 \pm 0.41$ & $11.73 \pm 0.17$ \\
\hline$\sum$ PUFA & & $68.98 \pm 2.22$ & $72.68 \pm 0.96$ \\
\hline$\sum$ UFA & & $70.81 \pm 2.56$ & $75.13 \pm 1.04$ \\
\hline Total FA & & $669.23 \pm 29.23$ & $546.97 \pm 13.82$ \\
\hline
\end{tabular}

Table 2: Fatty acid (FA) composition (\%) and total FAs relative intensities of $D$. salina cultivated under two conditions 

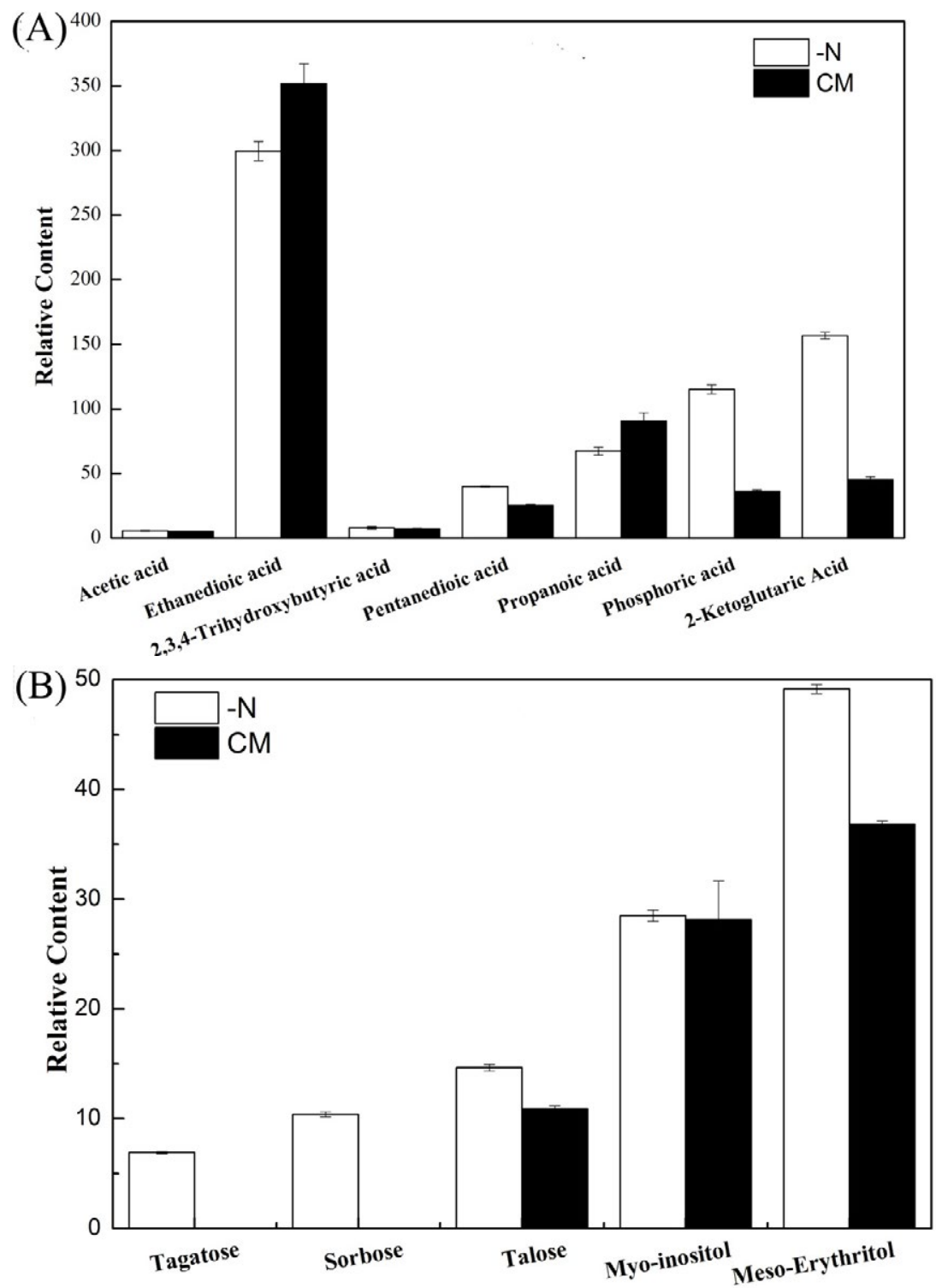

Figure 4: Organic acid (A) and protective components (B) identified in D. salina under $-\mathrm{N}$ and $\mathrm{CM}$ conditions

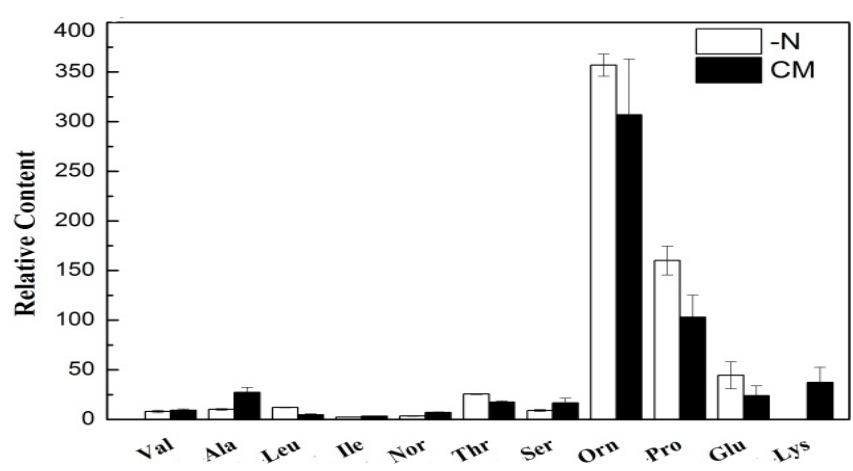

Val: Valine; Ala: Alanine; Leu: Leucine; Ile: Isoleucine; Ser: Serine; Orn: Ornithine Thr: Threonine; Pro: Proline; Glu: Glutamic acid; Lys: Lysine; The data shown are the averages $\pm S D$ of four replicates.

Figure 5: Amino acids identified in $D$. salina under $-\mathrm{N}$ and $\mathrm{CM}$ conditions.

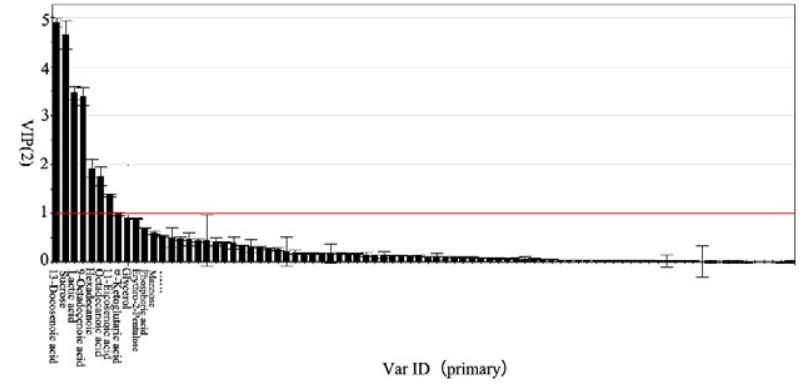

Figure 6: VIP results of samples from $D$. salina in two cultivation conditions.

\section{Acknowledgement}

This project was supported by the National Natural Science Foundation of China (No. 31401029) and the Foundation (No. 201502) of Tianjin Key Laboratory of Marine Resources and Chemistry (Tianjin University of Science and Technology), P. R. China. There are no conflicts of interest to declare. 
Citation: Lv H, Cui X, Wang S, Jia S, (2016) Metabolic Profiling of Dunaliella salina Shifting Cultivation Conditions to Nitrogen Deprivation. Metabolomics 6: 170. doi:10.4172/2153-0769.1000170

\section{References}

1. Lamers PP, Marcel J, Vos RCHD, Bino RJ, Wijffels RH (2012) Carotenoid and fatty acid metabolism in nitrogen-starved Dunaliella salina, a unicellular green microalga. J Biotechnol 162: 21-27.

2. Coesel SN, Baumgartner AC, Teles LM, Ramos AA, Henriques NM, et al. (2008) Nutrient limitation is the main regulatory factor for carotenoid accumulation and for Psy and Pds steady state transcript levels in Dunaliella salina (chlorophyta) exposed to high light and salt stress. Mar Biotechnol 10: 602-611.

3. Hosseini TA, Shariati, M (2009) Dunaliella biotechnology: methods and applications. J Appl Microbiol 107: 14-35.

4. Jayappriyan KR, Rajkumar R, Venkatakrishnan V, Nagaraj S, Rengasamy R (2013) In vitro anticancer activity of natural $\beta$-carotene from Dunaliella salina eu5891199 in pc-3 cells. Biomed Prev Nutr 3: 99-105.

5. Duc T, Nguyen D, Clifford L, Mario G, Sixto P (2014) Growth, antioxidant capacity and total carotene of Dunaliella salina dccbc15 in a low cost enriched natural seawater medium. World J Microb Biot 30: 317-322.

6. Ben-Amotz A, Avron M (1983) On the factors which determine massive carotene accumulation in the halo-tolerant alga Dunaliella bardawil. Plant Physiol 72: 593-597.

7. Hosseini TA, Shariati M (2009) Dunaliella biotechnology: methods and applications. J Appl Microbiol 107: 14-35.

8. Ben-Amotz A, Levy Y (1996) Bioavailability of a natural isomer mixture compared with synthetic all-trans $\beta$-carotene in human serum. Am J Clin Nutr 63: 729-34

9. Doddaiah KM, Narayan A, Aswathanarayana RG, Ravi S (2013) Effect of metabolic inhibitors on growth and carotenoid production in Dunaliella bardawil. J Food Sci Tech 50: 1130-1136.

10. Zhu YH, Jiang JG, Chen Q (2008) Influence of daily collection and culture medium recycling on the growth and beta-carotene yield of Dunaliella salina. J Agr Food Chem 56: 4027-4031.

11. Kacka A, Donmez G (2008) Isolation of Dunaliella spp. from a hypersaline lake and their ability to accumulate glycerol. Bioresource Technol 99: 8348-8352.

12. Lamers PP, Laak CCWVD, Kaasenbrood PS, Lorier J, Janssen M, et al (2010) Carotenoid and fatty acid metabolism in light-stressed Dunaliella salina. Biotechnol Bioeng 106: 638-648.

13. Borowitzka MA (1986) Vitamins and fine chemicals from microalgae. Cambridge University Press.

14. Villas-Bôas SG, Højer-Pedersen J, Akesson M, Smedsgaard J, Nielsen J (2005) Global metabolite analysis of yeast: evaluation of sample preparation methods. Yeast 22: 1155-1169.

15. Lu S, Wang J, Niu Y, Jie Y, Jian Z, et al. (2012) Metabolic profiling reveals growth related fame productivity and quality of chlorella sorokiniana with different inoculum sizes. Biotechnol Bioeng 109: 1651-1662.

16. Weckwerth W, Wenzel K, Fiehn O (2004) Process for the integrated extraction, identification and quantification of metabolites, proteins and rna to reveal their co-regulation in biochemical networks. Proteomics 4: 78-83.

17. Lee SY, Kim SH, Hyun SH, Suh HW, Hong SJ, et al. (2014) Fatty acids and global metabolites profiling of Dunaliella tertiolecta by shifting culture conditions to nitrate deficiency and high light at different growth phases. Process Biochem 49: 996-1004.

18. Liu M, Zhong C, Wu XY, Wei YQ, Bo T, et al. (2015) Metabolomic profiling coupled with metabolic network reveals differences in gluconacetobacter xylinus from static and agitated cultures. Biochem Eng J 101: 85-98.
19. Cakmak YS, Kaya M, Asan-Ozusaglam M (2014) Biochemical composition and bioactivity screening of various extracts from Dunaliella salina, a green microalga. EXCLI J 13: 679-690.

20. Srinivasan R, Kumar VA, Kumar D, Ramesh N, Babu S, et al. (2015) Effect of dissolved inorganic carbon on $\beta$-carotene and fatty acid production in Dunaliella sp. Appl Biochem Biotech 175: 2895-2906.

21. Renaud SM, Parry DL, Thinh LV (1994) Microalgae for use in tropical aquaculture i: gross chemical and fatty acid composition of twelve species of microalgae from the Northern Territory, Australia. J Appl Phycol 6: 337-345.

22. Cardozo KHM, Guaratini T, Barros MP, Falcão VR, Tonon AP, et al. (2007) Metabolites from algae with economical impact. Comp Biochem Physiol C Toxicol Pharmacol 146: 60-78.

23. Funk CD (2001) Prostaglandins and leukotrienes: advances in eicosanoid biology. Science 294: 1871-1875.

24. Srirangan S, Sauer ML, Howard B, Dvora M, Dums J, et al. (2015) Interaction of temperature and photoperiod increases growth and oil content in the marine microalgae Dunaliella viridis. Plos One 10

25. Gordillo FJL, Goutx M, Figueroa FL, Niell, FX (1998) Effects of light intensity $\mathrm{CO}_{2}$ and nitrogen supply on lipid class composition of Dunaliella viridis. J Appl Phycol 10: 135-144.

26. Meng C, Haiying T, Hongzhi M, Holland TC, Ng KY, Salley SO (2011) Effect of nutrients on growth and lipid accumulation in the green algae Dunaliella tertiolecta. Bioresour Technol 102: 1649-55.

27. Rabbani S, Beyer P, Lintig J, P Hugueney, Kleinig H (1998) Induced $\beta$-carotene synthesis driven by triacylglycerol deposition in the unicellular alga Dunaliella bardawil. Plant Physiol 116: 1239-1248.

28. Vidoudez C, Pohnert G (2011) Comparative metabolomics of the diatom Skeletonema marinoi in different growth phases. Metabolomics 8: 654-669.

29. Xia BB, Wang SH, Duan JB, Bai LH (2014) The relationship of glycerol and glycolysis metabolism pathway under hyperosmotic stress in Dunaliella salina. Cent Eur J Biol 9: 901-908.

30. Hui C, Yong-Min L, Jian GJ (2011) Effects of salinities on the gene expression of a (NAD+)-dependent glycerol-3-phosphate dehydrogenase in Dunaliella salina. Sci Total Environ 409: 1291-1297.

31. Vaughn MW, Harrington GN, Bush DR (2002) Sucrose-mediated transcriptiona regulation of sucrose symporter activity in the phloem. Proc Natl Acad Sci USA 99: 10876-10880.

32. Takagi H, Sakai K, Morida K, Nakamori S (2000) Proline accumulation by mutation or disruption of the proline oxidase gene improves resistance to freezing and desiccation stresses in Saccharomyces cerevisiae. Fems Microbiol Lett 184: 103-108.

33. Hiroshi T (2008) Proline as a stress protectant in yeast: physiological functions metabolic regulations, and biotechnological applications. Appl Microbiol Bio 81: $211-223$

34. He XJ, Mulford KE, Fassler JS (2009) Oxidative stress functions of the Saccharomyces cerevisiae Skn7 receiver domain. Eukaryot Cell 8: 768-778.

35. Rodrigues PCA, Nevitt T, Menezes R, Azevedo D, Pereira J, et al. (2004) Yeast activator proteins and stress response: an overview. FEBS Lett 567: 80-85. 